\title{
Designing the Optimal Digital Health Intervention for Patients' Use Before and After Elective Orthopedic Surgery: Qualitative Study
}

Anna Robinson ${ }^{1,2}$, MPharm, PGDip; Robert D Slight ${ }^{2,3}$, PhD; Andrew K Husband ${ }^{1,2}$, PhD; Sarah P Slight ${ }^{1,2}$, PhD

${ }_{1}^{1}$ School of Pharmacy, Newcastle University, Newcastle upon Tyne, United Kingdom
${ }^{2}$ Population Health Sciences Institute, Newcastle University, Newcastle upon Tyne, United Kingdom
${ }^{3}$ Newcastle upon Tyne Hospitals NHS Foundation Trust, Newcastle upon Tyne, United Kingdom

Corresponding Author:

Sarah P Slight, PhD

School of Pharmacy

Newcastle University

King George VI Building

Newcastle University

Newcastle upon Tyne, NE1 7RU

United Kingdom

Phone: 441912086000

Email: Sarah.slight@newcastle.ac.uk

\begin{abstract}
Background: Health behavior changes made by patients during the perioperative period can impact the outcomes and success of elective surgeries. However, there remains a limited understanding of how best to support patients during this time, particularly through the use of digital health interventions. Recognizing and understanding the potential unmet needs of elective orthopedic surgery patients is central to motivating healthier behavior change, improving recovery, and optimizing overall surgical success in the short and long term.
\end{abstract}

Objective: The aim of this study is to explore patient perspectives on technology features that would help support them to change their lifestyle behaviors during the pre- and postoperative periods, and that could potentially maintain long-term healthy lifestyles following recovery.

Methods: Semistructured interviews with pre- and postoperative elective orthopedic patients were conducted between May and June 2020 using telephone and video call-based software. Patient perspectives on the use of digital technologies to complement current surgical care and support with lifestyle behavior changes were discussed. Interviews were audio recorded and transcribed verbatim. Reflexive thematic analysis enabled the development of themes from the data, with QSR NVivo software (version 12) facilitating data management. Ethical approval was obtained from the National Health Service Health Research Authority.

Results: A total of 18 participants were interviewed. Four themes were developed from the data regarding the design and functionality of digital technologies to best support the perioperative journey. These center around an intervention's ability to incorporate interactive, user-centered features; direct a descriptive and structured recovery; enable customizable, patient-controlled settings; and deliver both general and specific surgical advice in a timely manner. Interventions that are initiated preoperatively and continued postoperatively were perceived as beneficial. Interventions designed with personalized milestones were found to better guide patients through a structured recovery. Individualized tailoring of preparatory and recovery information was desired by patients with previously high levels of physical activity before surgery. The use of personalized progression-based exercises further encouraged physical recovery; game-like rewards and incentives were regarded as motivational for making and sustaining health behavior change. In-built video calling and messaging features offered connectivity with peers and clinicians for supported care delivery.

Conclusions: Specific intervention design and functionality features can provide better, structured support for elective orthopedic patients across the entire surgical journey and beyond. This study provides much-needed evidence relating to the optimal design and timing of digital interventions for elective orthopedic surgical patients. Findings from this study suggest a desire for personalized perioperative care, in turn, supporting patients to make health behavior changes to optimize surgical success. These findings should be used to influence future co-design projects to enable the design and implementation of patient-focused, tailored, and targeted digital health technologies within modern health care settings. 
(J Med Internet Res 2021;23(3):e25885) doi: 10.2196/25885

\section{KEYWORDS}

digital technology; orthopedic surgery; behavior change; perioperative care; prehabilitation; qualitative research; mHealth; eHealth; mobile phone

\section{Introduction}

\section{Background}

Digital health technologies are becoming increasingly common in various industries, with medicine, surgery, and health care being no exception [1]. The use of digital health interventions is growing significantly among patients and health care providers, with recent studies reporting over 318,000 smartphone apps available to aid in health education, diagnosis, and self-management [2-4]. Despite the multitude of digital solutions available, many fail to meet patient and provider expectations - with their use and uptake hindered by ethical issues such as privacy and security of data, disease management, and communication [5]. Involving technology end users in cocreation approaches has been acknowledged as a possible strategy to design digital interventions that meet both the patient and provider needs $[6,7]$.

In recent digital health literature, there are various interventions that have successfully supported patients in managing long-term health conditions [8] and medication adherence [9,10] and supporting positive lifestyle behavior change before and after surgery to improve postoperative outcomes [11,12]. Health behavior changes made during the perioperative period can be fundamental in determining the outcomes and success of elective surgeries. In the context of orthopedic surgery, increases in preoperative physical activity levels and smoking cessation have been associated with improved postoperative bone healing [13], wound healing [14], quicker recovery times, and reduced pain scores [15]. Physical rehabilitation after orthopedic surgery is an essential component of treatment, as it helps to improve functional outcomes and support patients to return to their daily activities [16]. There remains a limited understanding of how best to support patients during this time, particularly through the use of digital interventions.

In this context, research has focused on the orthopedic clinician's use of digital technologies [1,17], for instance, in supporting their educational development [18], guiding clinical decision support [19], managing care referrals [20], and building the patient-clinician relationship [21,22]. Recognizing and understanding the potential unmet needs of elective orthopedic surgery patients is central to motivating healthier behavior change, improving their recovery, and optimizing overall surgical success in the short and long term [23-25]. The optimal design and functionality of digital solutions to aid this cohort are yet to be recognized.

\section{Objectives}

To develop useful and effective digital technologies and strategies, it is important to first understand how patients want to be supported on their care pathway. Our patient-informed research applies qualitative investigation to explore patient perspectives and identify key technology features that they would find supportive during the pre- and postoperative periods and that could potentially maintain long-term healthy lifestyles following recovery. Specifically, our key research questions concerned the following: (1) What do orthopedic patients want from digital health technologies? (2) How do they want to use them? and (3) When would they be of most benefit during their elective surgical journey?

\section{Methods}

\section{Recruitment and Sampling}

The Consolidated Criteria for Reporting Qualitative Research checklist was followed for this study, according to Enhancing the QUAlity and Transparency Of health Research guidelines (Multimedia Appendix 1) [26]. Immediately before study commencement, COVID-19 restrictions were enforced across the United Kingdom. This meant that the planned face-to-face recruitment and data collection could no longer be undertaken in person at one of the largest teaching hospitals in North England. Instead, an amendment to the National Health Service (NHS) Health Research Authority (HRA) Ethics meant that participants could be recruited remotely via email and social media. All participants were emailed with an information sheet detailing the purpose and aim of this study. Participants who expressed an interest and provided written consent were enrolled in the study. There was no prior relationship established between the researcher and participants before study commencement or recruitment. Inclusion criteria were as follows: participants aged more than 18 years who were due to undergo (or had recently undergone, within the last 2 years) elective orthopedic surgery, who were medically stable and did not have an acute decline in health away from their baseline, who were able to participate in an interview, who were able to communicate in English, and who had the capacity to consent to participate in the study. Purposive sampling was used to recruit participants undergoing a variety of orthopedic surgical procedures, with mixed age ranges and sociodemographic backgrounds.

\section{Semistructured Interviews}

In-depth, semistructured interviews were conducted by 1 researcher (AR, a female doctoral researcher with experience in qualitative research) between May and June 2020 while working from home. Interviews were conducted with participants over the telephone or by using video call-based software, such as Zoom and Microsoft Teams, and all participants were offered the choice of which they would prefer. The semistructured interview topic guide was developed based on 3 pilot interviews and covered key issues identified through a systematic literature review [12], meta-ethnography [27], and narrative review [28]. These issues included participants' understanding and experiences of surgery, awareness of perioperative lifestyle behavior change, perspectives on digital 
health technology use within the surgical pathways, and the optimal design of such technologies.

\section{Data Analysis}

All interviews were audio recorded and transcribed verbatim by 1 researcher (AR). All data were anonymized at the point of transcription; participants did not comment on the transcripts or provide feedback on results. Following reflexive thematic analysis processes, as defined by Braun and Clarke [29,30], each interview was transcribed and analyzed before conducting the next interview. The principle of constant comparison guided the iterative process of data collection and analysis. Two researchers (AR and $\mathrm{AH}$ ) performed a reflexive thematic analysis to analyze the data. Close and detailed reading of the transcripts allowed the 2 researchers to familiarize themselves with the data. Initial descriptive codes were identified in a systematic manner across the data set; these were then sorted into common coding patterns, which enabled the development of analytic themes from the data. The themes were reviewed, refined, and named once coherent and distinctive. Two authors (AR and $\mathrm{AH}$ ) performed the data analysis through discussion and, if agreement was not reached, by consensus with the wider research team (SS and RS). The postinterview field notes enhanced this reflective process. QSR NVivo software (version 12) was used to facilitate data management. The research team agreed that data saturation occurred in 18 interviews. To ensure confidentiality when using direct patient quotes within this research, nonidentifiable pseudonyms are used throughout, for example, participant 1 and participant 2.

\section{Ethical Approval}

Ethical approval was obtained from the NHS HRA and Care Research Wales (reference: 19/NE/0318), and research governance was granted by the participating NHS trust.

\section{Results}

\section{Overview}

A total of 18 participants were recruited and interviewed as part of this study (there were no refusals to partake, participant dropout, or repeat interviews). The characteristics of participants are presented in Table 1. The average age of the participants was 52 (SD 16.7) years, and the most common elective orthopedic procedure was a total hip replacement. A total of 11 interviews were conducted over the telephone and 7 were conducted using video call-based software. The average duration of the interview was 48 (SD 8.5) minutes.

Four themes were developed from the data (Figure 1) that addressed the aforementioned research questions. These themes centered on an intervention's ability to (1) incorporate interactive, user-centered features; (2) direct a descriptive and structured recovery; (3) enable customizable, patient-controlled settings; and (4) deliver both general and specific surgical advice in a timely manner. We will discuss each of these themes, in turn, illustrating patient perspectives and recommendations with direct interview quotes. 
Table 1. Participant characteristics.

\begin{tabular}{|c|c|c|c|c|c|c|}
\hline Participant number & $\operatorname{Sex}\left(\mathrm{M}^{\mathrm{a}}\right.$ or $\left.\mathrm{F}^{\mathrm{b}}\right)$ & Age (years) & Interview format & Orthopedic procedure & Pre- or postoperative & $\begin{array}{l}\text { Time since surgery } \\
\text { or time until surgery }\end{array}$ \\
\hline 1 & $\mathrm{~F}$ & 83 & Telephone & $\mathrm{TKR}^{\mathrm{c}}$ & Post & $12 \mathrm{~m}^{\mathrm{d}}$ \\
\hline 2 & M & 63 & Telephone & TKR & Post & $6 \mathrm{~m}$ \\
\hline 3 & M & 63 & Telephone & TKR & Post & $24 \mathrm{~m}$ \\
\hline 4 & $\mathrm{~F}$ & 41 & Video call & $\mathrm{THR}^{\mathrm{e}}$ & Post & $22 \mathrm{~m}$ \\
\hline 5 & $\mathrm{~F}$ & 42 & Video call & THR & Post & $14 \mathrm{~m}$ \\
\hline 6 & M & 61 & Telephone & THR & Post & $20 \mathrm{~m}$ \\
\hline 7 & M & 70 & Telephone & THR & Post & $16 \mathrm{~m}$ \\
\hline 8 & $\mathrm{~F}$ & 50 & Telephone & THR & Post & $8 \mathrm{~m}$ \\
\hline 9 & $\mathrm{~F}$ & 69 & Telephone & THR & Post & $24 \mathrm{~m}$ \\
\hline 10 & M & 50 & Video call & THR & Post & $10 \mathrm{~m}$ \\
\hline 11 & M & 66 & Telephone & TKR & Pre & $2 w^{f}$ \\
\hline 12 & M & 26 & Video call & Hip FAIS ${ }^{g}$ & Pre & $4 \mathrm{w}$ \\
\hline 13 & $\mathrm{~F}$ & 62 & Telephone & WL $R^{h}$ & Pre & $6 w$ \\
\hline 14 & M & 26 & Video call & ACL $R^{i}$ & Post & $6 w$ \\
\hline 15 & $\mathrm{~F}$ & 30 & Telephone & Ankle reconstruction & Pre & $1 \mathrm{w}$ \\
\hline 16 & M & 24 & Video call & ACL R & Post & $6 \mathrm{~m}$ \\
\hline 17 & M & 56 & Telephone & TKR & Pre & $3 w$ \\
\hline 18 & M & 54 & Video call & THR & Pre & $8 w$ \\
\hline
\end{tabular}

${ }^{\mathrm{a}} \mathrm{M}$ : male.

${ }^{\mathrm{b}} \mathrm{F}$ : female.

${ }^{\mathrm{c}}$ TKR: total knee replacement.

$\mathrm{d}_{\mathrm{m}}$ : months.

e THR: total hip replacement.

$\mathrm{f}_{\mathrm{w}}$ : weeks.

${ }^{\mathrm{g}}$ FAIS: femoral acetabular impingement surgery.

${ }^{\mathrm{h}}$ WL R: wrist ligament reconstruction.

${ }^{\mathrm{i}} \mathrm{ACL} \mathrm{R}$ : anterior cruciate ligament reconstruction. 
Figure 1. Features contributing to the design and functionality of digital technologies to best support orthopedic patients in their perioperative journey.

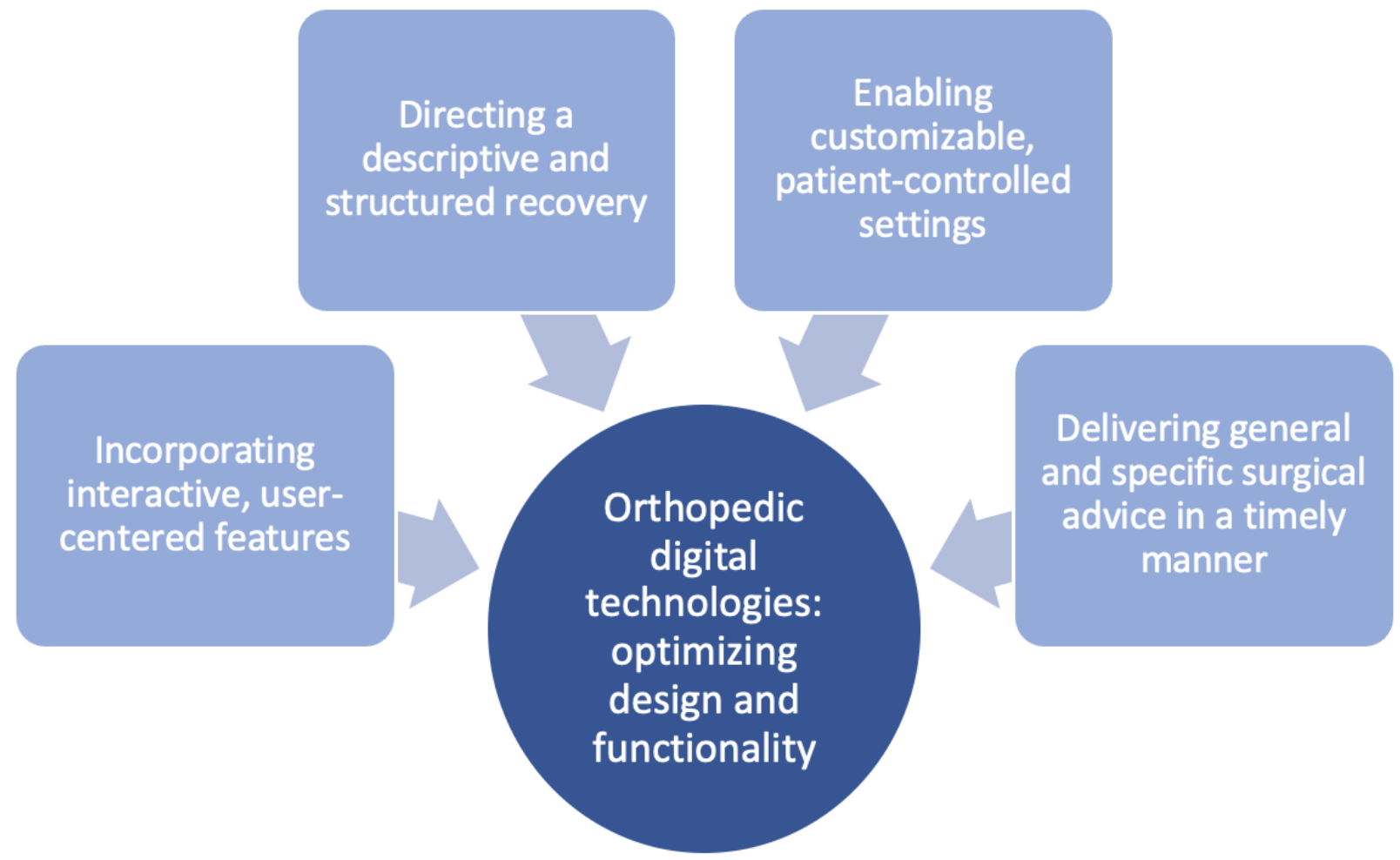

\section{Theme 1: Incorporating Interactive, User-Centered Features}

When considering what orthopedic patients wanted from digital technologies, it was important that the technology included features that centered on the needs of each user and were interactive in terms of logging and tracking and were visually instructive (video-based) and that allowed connectivity through messaging.

\section{Logging and Tracking Recovery}

Interviewees perceived numerous benefits from keeping logs during the perioperative period. In the first instance, they recognized personal benefits from "logging and tracking (their) recovery" (Participant 5) to visually "see your progress" (Participant 16) and "gauge where you are and how well you're doing" (Participant 4). This was viewed as something that would "give you the drive" to continue with the physical rehabilitation "to benefit yourself further" (Participant 9). Participants saw benefits in allowing members of the multidisciplinary team, such as surgeons and physiotherapists, to also view this information and "get an idea of when you're starting to improve" (Participant 13). Others expanded on this, seeing shared access as an opportunity to obtain further medical expert advice on "pains or swelling...and problems with the scar like any bleeding or signs of infection" (Participant 13) and find "reassurance" related to wound healing (Participant 10). Participants reflected on the accountability that can arise from shared access to logs, both as a form of intrinsic accountability to keep "helping yourself at home...to give yourself the best chance" in the recovery period (Participant 15) and as a way of "proving that you're doing what you're meant to" to their surgical team (Participant 13):
Things that record what you've done so you can see and say "ah, I've achieved that, I've done that"...I have the incentive to go further. [Participant 11]

Keeping a log of wider experiences during their perioperative journey, beyond physical activity, was also considered useful. A preoperative log of "mood, sleep deprivation and pain-management" strategies was considered important for participants to "validate your (their) mental-side" in the run-up to surgery (Participant 5). Two participants reflected on personal experiences that affected their mental health during the surgical journey, where "meditation or soothing-type app" features would have supported them "through particularly tough" preoperative pain, postoperative pain, and isolation during recovery (Participant 10). Another called for integration of an interactive "diary on the app...where you could type in how you feel...if there's any problems" alongside "logging the pain and the level of pain" (Participant 13).

Within the logging features, patients described in detail about the user-centered information they wished "to be told by the technology" (Participant 5). Emphasis was placed on "the specific tracking...of any (form of) activity," rather than only walking or running; being able to "compare your times or distances" (Participant 5) through "a graph or a visual" comparative feature (Participant 11); and having real-time functionality so that you can "track your progress accurately...like keeping track of your reps and weights" without relying on retrospective data entry (Participant 16). Participants also discussed share functions when it came to their logged activities where integrated competition features, such as "leader boards with friends" (Participant 12), appeared to add an incentive to engage with physiotherapy-based recovery. Combining these with "rewards and badges" (Participant 4) for 
logged activities appeared to reinforce patient motivation and engagement while keeping the technology user centered:

I'll think to myself "can I do it quicker, can I go further?"...which I think are all the correct messages one needs to hear when you put it in the context of general healthy living. [Participant 11]

\section{Want Something to Show Me}

Video features, as an interactive method of engaging with physical activity during the surgical journey, were discussed by all participants. Preoperatively, participants reflected that videos could be used to educate patients on "exercises they'll be expected to do" (Participant 5) and to build awareness around "the limitations, physically, that you will feel after the surgery" (Participant 8). Drawing on their experience, postoperative patients felt that being able to watch videos to practice rehabilitative exercises, preoperatively, would have given them "confidence and reassurance" to better engage with the recovery process from an earlier stage, optimizing "the entire recovery process, to give myself the best chance" (Participant 1). On the whole, participants felt video content to be of the highest value in the postoperative period, where patients can interact with instructional, surgery-specific rehabilitation advice by watching "user-friendly...video tutorials with people doing" the exercises (Participant 16). Participants discussed the integration of video-based postoperative "success stories" at various milestones of the recovery process, recognizing the power of video messages to help "visualize what you can achieve" (Participant 6) and "push me further with recovering" (Participant 16):

With each exercise there could be a video tutorial
with people doing them so you can go on, click, watch
the video...it could help you understand the exercise
the physio(therapist) recommends... and learn how to
do it properly so it's of most benefit. [Participant 16]

Along with using videos for instructional and educational purposes, participants reflected on their "changed views" (Participant 9) of integrating video call features in digital technologies for support during the perioperative period. For many, these views were linked to and influenced by the global COVID-19 pandemic. Participants described the usefulness of video calls, accepting them as a valuable and convenient form of communication while "getting used to a new normal, a different way of doing things with technology" (Participant 13). When discussing an upcoming preassessment appointment, one participant remarked that their preference for the consultation would be a video call in comparison with a proposed telephone call:

\section{I'd be more than happy with Skype to "see them" for my appointment...I think it's more personal, phone calls aren't personal...I'd much prefer to Skype now instead. [Participant 13]}

Two postoperative patients reflected on their current experiences of undergoing video-based physiotherapy sessions in light of COVID-19 measures. These participants remarked the following: [the content of the sessions] doesn't differ that much from actually being in-person-you can see everything well, the resolution is good and the picture is clear, I can hear clearly. [Participant 10]

everything we done the week before with the physio, we replicated on the Zoom call...everything that had been done in-person was quite easily done on the Zoom call. [Participant 14]

\section{Messaging Someone to Settle Your Nerves}

Participants felt that the inclusion of message-based features (whether with other patients or with health care professionals) within an intervention would offer numerous benefits. Preoperative participants expressed value in communicating with other people undergoing the same surgery. This related to information-seeking needs to learn from peers, with participants discussing how they already "have looked for blogs and posts from other people going through the operation" (Participant 12) and "asked for advice...to find out what the surgery is like" (Participant 13). Coupled with searching for educational support, preoperative patients reported seeking reassurance from others before undergoing the surgery, to hear "success stories (of) people who have gone through it successfully" (Participant 17) to support their surgical decision making. This was particularly important in younger participants who wished to discuss with patients of similar ages to ask "how quick their recovery was" (Participant 15) and the level to which they retained their physical activity and functioning following surgery. One participant described their preoperative nerves without knowing "what my life is going to look like after my surgery" and considered how "having a conversation or messaging someone to settle your nerves" could help (Participant 15).

Postoperatively, participants discussed the value of sharing "experiences on a forum" (Participant 7), suggesting the integration of a patient-led "discussion area" within an app "for people who've gone through similar surgeries-whatever question it may be, they can put it on there and receive feedback from people" (Participant 16). Participants demonstrated an awareness of "mis-information or mis-interpreting the information" that may be shared (Participant 16) and acknowledged how one could become easily "disillusioned" by comparing or "judging yourself on other people's recovery" (Participant 2). Both pre- and postoperative participants considered the morale boost that can come from communicating with peers, regardless of the stage of their surgical journey:

\section{It's harder when you're on your own, but when you're doing it alongside other people, having them to just be there as a point of reference or just to ask daft things to, that's much easier. [Participant 5]}

"Messaging features" (Participant 10) could also enable two-way interactivity between the patient and a member of the multidisciplinary team, where examples discussed took various forms, from real-time "live-chat boxes" (Participant 10) to "a personal account, like Facebook messenger" (Participant 13). It was important to specify response times when it came to seeking information in this manner, with some participants desiring an "instant reply from someone" (Participant 10) for emergency purposes such as "wound healing or infection" 
concerns (Participant 4), whereas others considered that a "response within 24 hours...or a defined period of time" for generic questions was suitable to "fit around the (professional's) workload" (Participant 16). Participants saw value in sharing both image- and text-based messages to aid clinical decision making, such as "how is your wound healing?" (Participant 10) or "identifying any signs of infection" (Participant 3), suggesting the value of visual connectivity in this cohort. Similar feelings of reassurance were also seen when participants discussed possible interactivity with members of the surgical multidisciplinary team:

Even the idea of (clinicians) saying "we're here, even though it's through technology"...it gives you a bit peace of mind. [Participant 9]

\section{Theme 2: Directing a Descriptive and Structured Recovery Plan}

Another important consideration of what this study wants from digital technologies was how directed, descriptive, and structured the content was. Perioperative participants expressed their desire for a digital intervention that could support them in "making the best recovery" by providing a structured and directed program with "suggestions of what you should be doing at each stage" (Participant 16). Postoperative patients discussed a "lack of direction" (Participant 16) in their current experiences following surgery, with extended periods between follow-up appointments where they lacked "the necessary, ongoing support" (Participant 2). One postoperative patient, 2 years after their total hip replacement, described gaps where "I was just winging it, really" in relation to recommended physiotherapy exercises:

\section{there was no kind of updates with stuff when I was at home. [Participant 9]}

Participants reported knowing "within each stage of recovery, you should be pushing a little bit more" (Participant 15) but felt unsupported to do this. This view was especially apparent in previously physically active patients and those of a younger demographic who wanted to be challenged further to restore "functionality in the joint after surgery" (Participant 12):

\section{all I was after was some indication of what to do to safely push on...having some indication of "this is what you need to do in this week, then move onto this"...I wanted something to show me. [Participant 4]}

Recommendations to provide this structured recovery program stemmed around designing "milestones...in terms of where you could expect to be after Week 1, Week 2," with the inclusion of "physiotherapy messages" (Participant 12) and "general healthy living messages" (Participant 11). Tailoring the intervention to support a structured recovery would mean starting with "simple exercises to start the recovery and build on from there" (Participant 16). Participants described the integration of gamification features and "progression-based exercises" throughout the recovery where, over time, the program recommended "trickier exercises...working towards that final goal of being recovered" (Participant 16). Both preand postoperative participants viewed the capability of setting "targets and goals to work towards" as an important feature of creating a structured and directed recovery program (Participant 4). Combining goal setting with gamification features to break "(rehabilitation) down into small chunks at the start, advancing through each level" (Participant 15) and real-time messages of support such as "well done, you've completed this level, next it's..." (Participant 4) were deemed motivational in giving "more people focus for what to achieve after the surgery" (Participant 5). Having a directed rehabilitation structure with set milestones to unlock over time also allowed participants "to feel some independence that it's up to you to advance through the levels or reach a certain target, but with the comfort of knowing it's still safe, you're not pushing too hard" (Participant 12). The incorporation of safety-netting features to recover at a safe speed also provided reassurance for preoperative patients that they will not be pushed to "do too much too soon" (Participant 12) and compromise their outcomes following surgery.

\section{Theme 3: Enabling Customizable, Patient-Controlled Settings}

When it came to addressing our research question of how patients wished to use these technologies, the benefits of having built-in, customizable, and "patient-controlled features" to enable elements of control were widely discussed (Participant 4). This ranged from wanting to "set myself my profile, choose my name..." (Participant 14) to having the ability to "build your own workout" (Participant 16) and "preference certain exercises to make it individualized to each person" (Participant 12). Interviewees perceived that customizable functionality would encourage greater engagement and a sense of accountability, meaning they better "connect with the (recovery) process" (Participant 4). One participant referenced the layout features of an app they were currently using, explaining how it was possible to "toggle the home-screen settings" to make it more personal (Participant 12):

\section{It's going to need a personal approach-but if you were able to toggle certain settings to make it individualized to each person, then you'll get more successful outcomes with it and impact different people in different ways. [Participant 12]}

Accompanying the ability to customize aspects of physical recovery, participants also recognized benefits in preferring features relating to the mental and motivational postsurgical journey. Choosing a "more personal reminder" (Participant 7) approach to notifications was deemed constructive and supportive, with encouraging messages of "have you done your physio yet?" rather than "automated "do your physio" notifications" (Participant 12).

Having the capacity to tailor preparatory and recovery information to individual participants was widely discussed-in particular, by those who described high levels of physical activity before surgery and a wish to continue this postoperatively:

\section{it completely depends on who you are as an individual and what you want from it (surgery) [Participant 4]}

Being able to "advance at a pace suitable for you" (Participant 12) during recovery was deemed imperative to restore previous 
"functionality of the joint" (Participant 6) and, in the process, meet individual postoperative expectations. From their experiences, some viewed rehabilitation exercises as "rather pedestrian" (Participant 6) and that "the whole process, the whole support...was geared around older and less mobile people" (Participant 4). It appeared that exercises were not designed with a younger or more active patient in mind. When it came to using technology to manage this, participants expressed desires to be able to "choose your own difficulty...to make the recovery challenging enough" (Participant 12):

(recommendations) should be determined by how active you already are...it's no good telling me "walk 1 mile" when I'm used to walking 20! It's the same for someone perhaps less active when they can't functionally do it. [Participant 4]

\section{Theme 4: Delivering General and Specific Surgical Advice in a Timely Manner}

Addressing our research question around when digital technologies would be of most benefit, the timing (initiation point) of the intervention appeared crucial. It was discussed that technology should be initiated to meet both the pre- and postoperative information-seeking needs of participants. Specifically, preoperative interviewees wished to have explicit "sections for before surgery" (Participant 11) to seek information about the surgical procedure, to understand the best way to prepare, and to familiarize themselves with the upcoming process of recovery so as to be "already in that mindset...to the idea of the time and energy we need to invest in order to fully recover" (Participant 17). On reflection, some postoperative patients felt that their recovery would have benefited from knowing this information in advance. "Staggering the information" was also considered important, with ideas of drip feeding and building up advice in the preoperative period so that postoperatively, they would be better prepared (Participant 10):

\section{I was ready for the off, straight away...I had it in my mind that that's what I needed to do...you don't want to be waiting 'til you're post (-operative) to hear those things. [Participant 5]}

Participants felt that the initiation of digital interventions should also be arranged with a sense of generalizability between surgical procedures so that patients undergoing any form of elective orthopedic surgery may find the preoperative information beneficial. Participants described the need for "a generic advice" hub (Participant 15) for all orthopedic patients to use, with "different tabs for different surgeries" so that patients could find surgery-specific information if they wanted (Participant 8). Two participants discussed the feasibility of having one "centralized database" (Participant 12) of exercises, breaking "the exercises down to different body parts," and being able to easily find those that they could do to aid their recovery (Participant 16). In addition, interviewees called for holistic "general health and recovery" sections, integrating "positive health advice" that would be useful to hear throughout the perioperative process of any surgery (Participant 6). This included preoperative advice on preparation for surgery and "building muscle strength beforehand" (Participant 15), reassurance on postoperative physical rehabilitation, and "shortand long-term messages" around overall healthy living (Participant 11):

There are generic exercises that would be recommended for most joint surgeries, just to build up the muscle strength again...(and) if you had an app where you could select "hip replacement" and it provided you with "this is what exercises you should do"...it could give you more specific information. [Participant 4]

\section{Discussion}

\section{Principal Findings}

This patient-informed study underlines the importance of obtaining orthopedic surgical patients' perspectives in relation to the design and functionality of digital technologies to best support their recovery. By collecting both pre- and postoperative patient perspectives, we were able to clearly identify specific features and functionalities that appear to be the most desired and of most benefit in supporting this surgical cohort across the whole perioperative pathway. We addressed 3 research areas: what patients wanted from digital technologies, how they wanted to use them, and when their use would be of most benefit.

A consistent finding across interviews was that participants saw value in having a digital intervention to direct them through a structured plan to achieve a successful recovery. In terms of technology design, both prescriptive and descriptive contents were desired, where participants called for regular digital milestones to guide them and measure their journey toward recovery. Previous studies have demonstrated the benefits of continuous measurement within the recovery process following cardiac [31] and neurological surgery [32]. This feature should be considered for orthopedic interventions, where quantifying the progress can motivate patients to take active roles in their recovery [33]. Mehta et al [34] aligned this idea with reports of positive reinforcement by setting and meeting individual recovery goals following hip arthroplasty. Goal setting is a well-recognized behavior change technique that supports self-regulation skills in the change process $[35,36]$. In previous orthopedic studies, digital goal setting facilitated personal fulfillment and provided patients with a sense of control and accomplishment during the perioperative period $[37,38]$. Combining goal setting with performance feedback and the review of goals (akin to milestones within the recovery journey) has been associated with both short- and long-term intervention effectiveness [39,40]. Personalized and tailored feedback on these goals could be acknowledged as relevant and actionable, as opposed to generic advice [41]. By integrating digital strategies to help define goals within recovery, orthopedic patients may feel better supported and motivated to engage in health behavior change.

Participants valued the integration of video-based features in digital interventions, whether as a visual aid for rehabilitative exercises or to facilitate remote telemedicine consultations. Our findings support the growing popularity of video-based consultations reported in other areas of global health and social care [42-44], with participants reporting feelings of 
connectedness, empowerment, and reassurance through imageand video-based sharing [45-47]. The incorporation of video call features within digital health technology is gaining attention, particularly as a consequence of the global COVID-19 pandemic $[43,48]$. It appeared that the more prominent use of video call features, both in participants' work and social lives, has led to greater acceptance and adoption of their use within the world of health care [48].

Another promising strategy of digital intervention design, gamification, has also been linked to increased user engagement $[49,50]$. In this study, participants' suggestions to incorporate leaderboards and collect rewards during the postoperative recovery process echo recent findings from adult and pediatric patients undergoing orthopedic, dental, and ophthalmic surgeries $[51,52]$ and those concerning wider eHealth design $[40,53]$. The use of game-like rewards and incentives has been shown to motivate and sustain health habits over time [54,55]. In wider public health initiatives, incentive-based health apps and activity-tracking programs have been associated with positive physical activity behavior change in Canada [56] and the United Kingdom [57,58]. Other successful digital health interventions have incorporated gamification features, promoting intrinsic and extrinsic motivators [59-61]. Similarities can also be recognized between these findings and wider work on persuasive systems design in relation to shaping health behaviors during the perioperative period [62-66]. Oinas-Kukkonen and Harjumaa [62] proposed that persuasion principles (including praise and rewards) should be considered as requirements in software design.

This study contributes further evidence to support gaps in the literature, which relate to the timing of intervention use, including the initiation and continuation points of intervention use. This gap has also been acknowledged in recent systematic reviews and research by Jansson et al [16], Mirkovic et al [67], and our research team [12,27]. Interventions that are initiated preoperatively and continued postoperatively were perceived as beneficial. Captivating the preoperative patient mindset and making use of the surgical teachable moment appears to be significant in encouraging perioperative behavior change and optimizing postoperative outcomes [68]. Being granted a sense of control and responsibility over their recovery by initiating and using interventions preoperatively were valued by participants. Before surgery, interviewees described the desire to customize their technology and its content to best suit their needs, thereby encouraging better engagement with the upcoming recovery process. The individualization of care pathways has been discussed in medical and surgical literature $[69,70]$; however, our study also highlights the importance of individualization of the technologies to support care delivery. Technologies that incorporated customizable features, which the patient could control and toggle according to their personal preferences, were considered another motivator for successful recovery. Participant autonomy has been shown to positively impact motivation levels and user experience, thereby improving patient care experiences [71-73]. Technology-enabled, preference-based care has improved patient and health care professional outcomes [72-74]. Technology creators may consider implementing customizable features to grant patients autonomy over aspects of their recovery $[67,75]$.

All participants in this study discussed the impact of the global COVID-19 pandemic on the UK NHS. At the point of interview, 3 participants were undergoing technology-enabled follow-up appointments with their physiotherapist and 2 had used video call-based software to conduct their preoperative assessments with members of the surgical multidisciplinary team. Participants' views echoed those discussed in this study on digitally engaged patients and recognized the multitude of ways in which technologies can be embedded within the NHS to transform surgical patient support throughout the entire perioperative journey [48]. Interactive health technologies have been credited as transformers of health care by supporting engaged self-care and promoting positive health behaviors [76]. The global pandemic has presented a unique opportunity for the creative delivery of health care. It is important that this momentum gained to adopt and use digital technologies is not lost, with the focus being continued provision of innovative surgical patient care, monitoring, and follow-up spanning the whole perioperative period [77].

\section{Limitations}

We acknowledge that there are some limitations with this study. The intended method of in-person data collection was impacted by the COVID-19 pandemic. Although virtual call-based software enabled the replication of face-to-face interviews (ie, responding to verbal and nonverbal cues and building rapport) $[78,79]$, there are some disadvantages to this interview technique that may have impacted our study. Established familiarity and participant comfort of use may have resulted in the higher number of interviews conducted over the telephone. Despite this, video calls enabled a unique snapshot into life of a patient recovering at home during the crisis and provided a fuller picture with more context than a telephone call may have done [80]. Participants currently experiencing remote consultations with members of the surgical team offered timely insights into this study. As a result of the COVID-19 pandemic, many elective orthopedic surgeries were canceled, which meant that fewer preoperative participants could be recruited and interviewed in comparison with postoperative participants. This study predominantly focused on a small sample of patients in Northern England, and as a result, the experiences shared by participants may not be representative of all care pathways across the United Kingdom. This study also focused solely on the perspectives of elective orthopedic surgical patients, and thus, the results may not be generalizable to other elective surgical specialties or acute surgeries.

\section{Conclusions}

The results of this study have important implications for the design, functionality, application, and use of digital technologies for patients undergoing elective orthopedic surgery. By integrating digital goal-setting strategies within their recovery, patients feel better supported and motivated to engage in health behavior change to optimize surgical outcomes. The use of game-like rewards and incentives has been seen to motivate and sustain positive health habits over time. The integration of video features was acknowledged as an interactive method of engaging 
with physical activity during recovery and is regarded as a more personal strategy to enable follow-up consultations. This study contributes to the limited amount of existing digital health literature in this patient cohort and provides much-needed evidence relating to the optimal timing of digital interventions for elective orthopedic surgical patients. These findings should be employed in future codesign projects to enable the design and implementation of patient-focused, tailored, and targeted digital health technologies within modern health care settings.

\section{Conflicts of Interest}

None declared.

\section{Multimedia Appendix 1}

Consolidated Criteria for Reporting Qualitative Research: 32-item checklist.

[DOCX File , 23 KB-Multimedia Appendix 1]

\section{References}

1. Al-Obaidi B, Babu S, Al-Hadithy N. Smartphones in orthopaedics: a decade of innovation. Br J Hosp Med (Lond) 2019 May 02;80(5):274-277. [doi: 10.12968/hmed.2019.80.5.274] [Medline: 31059338]

2. The growing value of digital health in the United Kingdom. The IQVIA Institute. 2017 Nov 01. URL: https://www.iqvia.com/ insights/the-iqvia-institute/reports/the-growing-value-of-digital-health-in-the-united-kingdom [accessed 2021-02-02]

3. Armstrong KA, Coyte PC, Brown M, Beber B, Semple JL. Effect of home monitoring via mobile app on the number of in-person visits following ambulatory surgery: a randomized clinical trial. JAMA Surg 2017 Mar 22;152(7):622-627. [doi: 10.1001/jamasurg.2017.0111] [Medline: 28329223]

4. Schnall R, Mosley JP, Iribarren SJ, Bakken S, Carballo-Diéguez A, Brown IW. Comparison of a user-centered design, self-management app to existing mhealth apps for persons living with HIV. JMIR Mhealth Uhealth 2015;3(3):e91 [FREE Full text] [doi: 10.2196/mhealth.4882] [Medline: 26385783]

5. Birnbaum F, Lewis D, Rosen RK, Ranney ML. Patient engagement and the design of digital health. Acad Emerg Med 2015 Jun;22(6):754-756 [FREE Full text] [doi: 10.1111/acem.12692] [Medline: 25997375]

6. Brennan L, Kessie T, Caulfield B. Patient experiences of rehabilitation and the potential for an mHealth system with biofeedback after breast cancer surgery: qualitative study. JMIR Mhealth Uhealth 2020 Jul 29;8(7):e19721 [FREE Full text] [doi: $\underline{10.2196 / 19721]}$ [Medline: $\underline{32687476}$ ]

7. Burns D, Razmjou H, Shaw J, Richards R, McLachlin S, Hardisty M, et al. Adherence tracking with smart watches for shoulder physiotherapy in rotator cuff pathology: protocol for a longitudinal cohort study. JMIR Res Protoc 2020 Jul 05;9(7):e17841 [FREE Full text] [doi: 10.2196/17841] [Medline: 32623366]

8. Apolinário-Hagen J, Menzel M, Hennemann S, Salewski C. Acceptance of mobile health apps for disease management among people with multiple sclerosis: web-based survey study. JMIR Form Res 2018 Dec 12;2(2):e11977 [FREE Full text] [doi: 10.2196/11977] [Medline: 30684408]

9. Santo K, Singleton A, Rogers K, Thiagalingam A, Chalmers J, Chow CK, et al. Medication reminder applications to improve adherence in coronary heart disease: a randomised clinical trial. Heart 2019 Feb 27;105(4):323-329. [doi: 10.1136/heartjnl-2018-313479] [Medline: $\underline{\text { 30150326] }}$

10. Sua YS, Jiang Y, Thompson DR, Wang W. Effectiveness of mobile phone-based self-management interventions for medication adherence and change in blood pressure in patients with coronary heart disease: a systematic review and meta-analysis. Eur J Cardiovasc Nurs 2020 Mar 19;19(3):192-200. [doi: 10.1177/1474515119895678] [Medline: 31856596]

11. McDonald S, Yates D, Durrand JW, Kothmann E, Sniehotta FF, Habgood A, et al. Exploring patient attitudes to behaviour change before surgery to reduce peri-operative risk: preferences for short- vs. long-term behaviour change. Anaesthesia 2019 Dec 21;74(12):1580-1588 [FREE Full text] [doi: 10.1111/anae.14826] [Medline: $\underline{31637700}$ ]

12. Robinson AH, Husband AK, Slight RD, Slight SP. Effectiveness of digital technologies to support surgical patients in changing their health behaviours: a systematic review. BJS Open 2020 Dec 28:1-4 [FREE Full text] [doi: 10.1093/bjsopen/zraa009]

13. Truntzer J, Vopat B, Feldstein M, Matityahu A. Smoking cessation and bone healing: optimal cessation timing. Eur J Orthop Surg Traumatol 2015 Feb 31;25(2):211-215. [doi: 10.1007/s00590-014-1488-y] [Medline: 24879610]

14. Sørensen LT. Wound healing and infection in surgery. The clinical impact of smoking and smoking cessation: a systematic review and meta-analysis. Arch Surg 2012 Apr 01;147(4):373-383. [doi: 10.1001/archsurg.2012.5] [Medline: 22508785]

15. Luna IE, Kehlet H, Wede HR, Hoevsgaard SJ, Aasvang EK. Objectively measured early physical activity after total hip or knee arthroplasty. J Clin Monit Comput 2019 Jun 23;33(3):509-522. [doi: 10.1007/s10877-018-0185-5] [Medline: 30039461]

16. Jansson MM, Rantala A, Miettunen J, Puhto A, Pikkarainen M. The effects and safety of telerehabilitation in patients with lower-limb joint replacement: a systematic review and narrative synthesis. J Telemed Telecare 2020 Apr 21:1357633X20917868. [doi: 10.1177/1357633X20917868] [Medline: 32316837]

17. Popat R, Mohan AT, Branford OA. Current uses of smartphones and apps in orthopaedic surgery. Br J Hosp Med (Lond) 2013 Dec;74(12):672-676. [doi: 10.12968/hmed.2013.74.12.672] [Medline: 24326713] 
18. Chen EA, Ellahie A, Barsi J. Smartphone applications in orthopaedic surgery: a review of the literature and application analysis. Current Orthopaedic Practice 2019;30:230. [doi: 10.1097/bco.0000000000000745]

19. Watson HA, Tribe RM, Shennan AH. The role of medical smartphone apps in clinical decision-support: a literature review. Artif Intell Med 2019 Sep;100:101707-101704. [doi: 10.1016/j.artmed.2019.101707] [Medline: 31607347]

20. Morkel RW, Mann TN, Du Preez G, Du Toit J. Orthopaedic referrals using a smartphone app: uptake, response times and outcome. S Afr Med J 2019 Oct 31;109(11):859. [doi: 10.7196/samj.2019.v109i11.13986]

21. De La Cruz Monroy MFI, Mosahebi A. The use of smartphone applications (Apps) for enhancing communication with surgical patients: a systematic review of the literature. Surg Innov 2019 Apr;26(2):244-259. [doi: 10.1177/1553350618819517] [Medline: $\underline{30602332]}$

22. Sharif FS, Rahman A, Tonner E, Ahmed H, Haq I, Abbass R, et al. Can technology optimise the pre-operative pathway for elective hip and knee replacement surgery: a qualitative study. Perioper Med (Lond) 2020 Nov 16;9(1):33 [FREE Full text] [doi: 10.1186/s13741-020-00166-0] [Medline: 33292556]

23. Tang M, Li Z, Dai Y, Li X. What kind of a mobile health app do patients truly want? A pilot study among ambulatory surgery patients. Patient Prefer Adherence 2019;13:2039-2046 [FREE Full text] [doi: 10.2147/PPA.S220207] [Medline: 31824139]

24. Datillo JR, Gittings DJ, Sloan M, Hardaker WM, Deasey MJ, Sheth NP. "Is There An App For That?" Orthopaedic patient preferences for a smartphone application. Appl Clin Inform 2017 Aug 16;8(3):832-844 [FREE Full text] [doi: 10.4338/ACI-2017-04-RA-0058] [Medline: 28885637]

25. Michard F, Gan T, Kehlet H. Digital innovations and emerging technologies for enhanced recovery programmes. Br J Anaesth 2017 Jul 01;119(1):31-39 [FREE Full text] [doi: 10.1093/bja/aex140] [Medline: 28605474]

26. Tong A, Sainsbury P, Craig J. Consolidated criteria for reporting qualitative research (COREQ): a 32-item checklist for interviews and focus groups. Int J Qual Health Care 2007 Dec;19(6):349-357. [doi: 10.1093/intqhc/mzm042] [Medline: 17872937]

27. Robinson A, Oksuz U, Slight R, Slight S, Husband A. Digital and Mobile Technologies to Promote Physical Health Behavior Change and Provide Psychological Support for Patients Undergoing Elective Surgery: Meta-Ethnography and Systematic Review. JMIR Mhealth Uhealth 2020 Dec 01;8(12):e19237 [FREE Full text] [doi: 10.2196/19237] [Medline: 33258787]

28. Robinson A, Husband AK, Slight RD, Slight SP. Digital support for patients undergoing bariatric surgery: narrative review of the roles and challenges of online forums. JMIR Perioper Med 2020 Jul 15;3(2):e17230 [FREE Full text] [doi:

10.2196/17230] [Medline: 33393926]

29. Braun V, Clarke V. Reflecting on reflexive thematic analysis. Qualitative Research in Sport, Exercise and Health 2019 Jun 13;11(4):589-597. [doi: 10.1080/2159676x.2019.1628806]

30. Braun V, Clarke V. What can "thematic analysis" offer health and wellbeing researchers? Int J Qual Stud Health Well-being 2014;9:26152 [FREE Full text] [doi: 10.3402/qhw.v9.26152] [Medline: 25326092]

31. Cook DJ, Thompson JE, Prinsen SK, Dearani JA, Deschamps C. Functional recovery in the elderly after major surgery: assessment of mobility recovery using wireless technology. Ann Thorac Surg 2013 Sep;96(3):1057-1061. [doi: 10.1016/j.athoracsur.2013.05.092] [Medline: 23992697]

32. Appelboom G, Taylor BE, Bruce E, Bassile CC, Malakidis C, Yang A, et al. Mobile phone-connected wearable motion sensors to assess postoperative mobilization. JMIR Mhealth Uhealth 2015 Jul 28;3(3):e78 [FREE Full text] [doi: 10.2196/mhealth.3785] [Medline: 26220691]

33. Lyman S, Hidaka C, Fields K, Islam W, Mayman D. Monitoring patient recovery after THA or TKA using mobile technology. HSS J 2020 Dec;16(Suppl 2):358-365. [doi: 10.1007/s11420-019-09746-3] [Medline: 33380968]

34. Mehta N, Steiner C, Fields KG, Nawabi DH, Lyman SL. Using mobile tracking technology to visualize the trajectory of recovery after hip arthroscopy: a case report. HSS J 2017 Jul;13(2):194-200 [FREE Full text] [doi: 10.1007/s11420-017-9544-x] [Medline: 28690471]

35. Michie S, Whittington C, Hamoudi Z, Zarnani F, Tober G, West R. Identification of behaviour change techniques to reduce excessive alcohol consumption. Addiction 2012 Aug;107(8):1431-1440. [doi: 10.1111/j.1360-0443.2012.03845.x] [Medline: 22340523]

36. Michie S, van Stralen MM, West R. The behaviour change wheel: a new method for characterising and designing behaviour change interventions. Implement Sci 2011 Apr 23;6:42 [FREE Full text] [doi: 10.1186/1748-5908-6-42] [Medline: 21513547]

37. Argent R, Slevin P, Bevilacqua A, Neligan M, Daly A, Caulfield B. Wearable sensor-based exercise biofeedback for orthopaedic rehabilitation: a mixed methods user evaluation of a prototype system. Sensors (Basel) 2019 Jan 21;19(2):1-432 [FREE Full text] [doi: 10.3390/s19020432] [Medline: 30669657]

38. Lee M, Suh D, Son J, Kim J, Eun S, Yoon B. Patient perspectives on virtual reality-based rehabilitation after knee surgery: importance of level of difficulty. J Rehabil Res Dev 2016;53(2):239-252 [FREE Full text] [doi: 10.1682/JRRD.2014.07.0164] [Medline: 27149529]

39. Michie S, Abraham C, Whittington C, McAteer J, Gupta S. Effective techniques in healthy eating and physical activity interventions: a meta-regression. Health Psychol 2009 Nov;28(6):690-701. [doi: 10.1037/a0016136] [Medline: 19916637]

40. Jessen S, Mirkovic J, Ruland CM. Creating gameful design in mhealth: a participatory co-design approach. JMIR Mhealth Uhealth 2018 Dec 14;6(12):e11579 [FREE Full text] [doi: 10.2196/11579] [Medline: $\underline{30552080]}$ 
41. Amann J, Fiordelli M, Scheel-Sailer A, Brach M, Rubinelli S. Opportunities and challenges of a self-management app to support people with spinal cord injury in the prevention of pressure injuries: qualitative study. JMIR Mhealth Uhealth 2020 Dec 09;8(12):e22452 [FREE Full text] [doi: 10.2196/22452] [Medline: 33295876]

42. Barsom EZ, Jansen M, Tanis PJ, van de Ven AWH, Blussé van Oud-Alblas M, Buskens CJ, et al. Video consultation during follow up care: effect on quality of care and patient- and provider attitude in patients with colorectal cancer. Surg Endosc 2021 Mar;35(3):1278-1287. [doi: 10.1007/s00464-020-07499-3] [Medline: 32198552]

43. Li HL, Chan YC, Huang JX, Cheng SW. Pilot study using telemedicine video consultation for vascular patients' care during the Covid-19 period. Ann Vasc Surg 2020 Oct;68:76-82 [FREE Full text] [doi: 10.1016/j.avsg.2020.06.023] [Medline: 32562832]

44. Rabinovich L, Molton JS, Ooi WT, Paton NI, Batra S, Yoong J. Perceptions and acceptability of digital interventions among tuberculosis patients in cambodia: qualitative study of video-based directly observed therapy. J Med Internet Res $2020 \mathrm{Jul}$ 27;22(7):e16856 [FREE Full text] [doi: 10.2196/16856] [Medline: 32716309]

45. Hasselberg M, Beer N, Blom L, Wallis LA, Laflamme L. Image-based medical expert teleconsultation in acute care of injuries. A systematic review of effects on information accuracy, diagnostic validity, clinical outcome, and user satisfaction. PLoS One 2014;9(6):e98539 [FREE Full text] [doi: 10.1371/journal.pone.0098539] [Medline: 24887257]

46. Vlahu-Gjorgievska E, Nagapuri S, Win KT. Tele-monitoring technology as a tool for monitoring and management of patients with congestive heart failure. Acad J Interdiscip Stud 2019 Feb 12;23:e1. [doi: 10.3127/ajis.v23i0.1816]

47. Almathami HKY, Win KT, Vlahu-Gjorgievska E. Barriers and facilitators that influence telemedicine-based, real-time, online consultation at patients' homes: systematic literature review. J Med Internet Res 2020 Feb 20;22(2):e16407 [FREE Full text] [doi: 10.2196/16407] [Medline: $\underline{\text { 32130131] }}$

48. Sahu D, Rathod V. Telerehabilitation during COVID 19: Shoulder rehabilitation: letter to the editor regarding Menendez et al: "Orthopedic surgery post COVID-19: an opportunity for innovation and transformation". J Shoulder Elbow Surg 2020 Oct;29(10):1957-1958 [FREE Full text] [doi: 10.1016/j.jse.2020.07.001] [Medline: 32659460]

49. Cugelman B. Gamification: what it is and why it matters to digital health behavior change developers. JMIR Serious Games 2013 Dec 12;1(1):e3 [FREE Full text] [doi: 10.2196/games.3139] [Medline: 25658754]

50. Cotton V, Patel MS. Gamification use and design in popular health and fitness mobile applications. Am J Health Promot 2019 Mar;33(3):448-451 [FREE Full text] [doi: 10.1177/0890117118790394] [Medline: 30049225]

51. Kontadakis G, Chasiouras D, Proimaki D, Halkiadakis M, Fyntikaki M, Mania K. Gamified platform for rehabilitation after total knee replacement surgery employing low cost and portable inertial measurement sensor node. Multimed Tools Appl 2018 Sep 12;79(5-6):3161-3188. [doi: 10.1007/s11042-018-6572-6]

52. Ryu JH, Park JW, Nahm FS, Jeon YT, Oh AY, Lee HJ, et al. The effect of gamification through a virtual reality on preoperative anxiety in pediatric patients undergoing general anesthesia: a prospective, randomized, and controlled trial. J Clin Med 2018 Sep 17;7(9):284 [FREE Full text] [doi: 10.3390/jcm7090284] [Medline: 30227602]

53. Jessen S, Mirkovic J, Nes LS. Mystrengths, a strengths-focused mobile health tool: participatory design and development. JMIR Form Res 2020 Jul 24;4(7):e18049 [FREE Full text] [doi: 10.2196/18049] [Medline: 32706651]

54. King D, Greaves F, Exeter C, Darzi A. 'Gamification': influencing health behaviours with games. J R Soc Med 2013 Mar;106(3):76-78 [FREE Full text] [doi: 10.1177/0141076813480996] [Medline: 23481424]

55. Lister C, West JH, Cannon B, Sax T, Brodegard D. Just a fad? Gamification in health and fitness apps. JMIR Serious Games 2014 Aug 04;2(2):e9 [FREE Full text] [doi: 10.2196/games.3413] [Medline: 25654660]

56. Mitchell M, White L, Lau E, Leahey T, Adams MA, Faulkner G. Evaluating the carrot rewards app, a population-level incentive-based intervention promoting step counts across two canadian provinces: quasi-experimental study. JMIR Mhealth Uhealth 2018 Sep 20;6(9):e178 [FREE Full text] [doi: 10.2196/mhealth.9912] [Medline: 30148712]

57. Elliott M, Eck F, Khmelev E, Derlyatka A, Fomenko O. Physical activity behavior change driven by engagement with an incentive-based app: evaluating the impact of sweatcoin. JMIR Mhealth Uhealth 2019 Jul 08;7(7):e12445 [FREE Full text] [doi: 10.2196/12445] [Medline: 31287064]

58. Hajat C, Hasan A, Subel S, Noach A. The impact of short-term incentives on physical activity in a UK behavioural incentives programme. NPJ Digit Med 2019 Sep 16;2(1):91 [FREE Full text] [doi: 10.1038/s41746-019-0164-3] [Medline: 31531396]

59. Fox LG, Barnes D. Boosterbuddy: using gamification as a compensatory strategy for motivational deficits. Psychiatr Serv 2016 Jan;67(1):141-142. [doi: 10.1176/appi.ps.661101] [Medline: 26725495]

60. Roepke AM, Jaffee SR, Riffle OM, McGonigal J, Broome R, Maxwell B. Randomized controlled trial of superbetter, a smartphone-based/internet-based self-help tool to reduce depressive symptoms. Games Health J 2015 Jun;4(3):235-246. [doi: 10.1089/g4h.2014.0046] [Medline: 26182069]

61. Edwards EA, Lumsden J, Rivas C, Steed L, Edwards LA, Thiyagarajan A, et al. Gamification for health promotion: systematic review of behaviour change techniques in smartphone apps. BMJ Open 2016 Oct 04;6(10):e012447 [FREE Full text] [doi: 10.1136/bmjopen-2016-012447] [Medline: 27707829]

62. Oinas-Kukkonen H, Harjumaa M. Persuasive systems design: key issues, process model, and system features. Commun Assoc Inf Syst 2009;24:e1. [doi: 10.17705/1cais.02428]

63. Parada F, Martínez V, Espinosa HD, Bauer S, Moessner M. Using persuasive systems design model to evaluate. Telemed J E Health 2020 Feb;26(2):251-254 [FRE Full text] [doi: 10.1089/tmj.2018.0272] [Medline: 30668227] 
64. Hassan L, Xi N, Gurkan B, Koivisto J, Hamari J. Gameful self-regulation: a study on how gamified self-tracking features evoke gameful experiences. In: Proceedings of the 53rd Hawaii International Conference on System Sciences. 2020 Presented at: 53rd Hawaii International Conference on System Sciences; Jan 7-10, 2020; Maui, Hawaii p. 1-10 URL: https://tinyurl. com/3yprrpa2 [doi: 10.24251/hicss.2020.138]

65. Asbjørnsen RA, Wentzel J, Smedsrød ML, Hjelmesæth J, Clark MM, Solberg Nes L, et al. Identifying persuasive design principles and behavior change techniques supporting end user values and needs in ehealth interventions for long-term weight loss maintenance: qualitative study. J Med Internet Res 2020 Nov 30;22(11):e22598 [FREE Full text] [doi: 10.2196/22598] [Medline: 33252347$]$

66. Kelders SM, Kok RN, Ossebaard HC, Van Gemert-Pijnen JEWC. Persuasive system design does matter: a systematic review of adherence to web-based interventions. J Med Internet Res 2012 Nov 14;14(6):e152 [FREE Full text] [doi: 10.2196/jmir.2104] [Medline: 23151820]

67. Mirkovic J, Kristjansdottir OB, Stenberg U, Krogseth T, Stange KC, Ruland CM. Patient insights into the design of technology to support a strengths-based approach to health care. JMIR Res Protoc 2016 Aug 24;5(3):e175 [FREE Full text] [doi: 10.2196/resprot.5906] [Medline: 27558951]

68. Robinson A, Slight R, Husband A, Slight S. The value of teachable moments in surgical patient care and the supportive role of digital technologies. Perioper Med (Lond) 2020;9:2 [FREE Full text] [doi: 10.1186/s13741-019-0133-z] [Medline: 32042404]

69. Grocott MPW, Edwards M, Mythen MG, Aronson S. Peri-operative care pathways: re-engineering care to achieve the 'triple aim'. Anaesthesia 2019 Jan 02;74 Suppl 1:90-99 [FREE Full text] [doi: 10.1111/anae.14513] [Medline: 30604413]

70. Levy N, Grocott MPW, Carli F. Patient optimisation before surgery: a clear and present challenge in peri-operative care. Anaesthesia 2019 Jan;74 Suppl 1:3-6 [FREE Full text] [doi: 10.1111/anae.14502] [Medline: $\underline{30604412}$ ]

71. Güldenpfennig F, Mayer P, Panek P, Fitzpatrick G. An autonomy-perspective on the design of assistive technology experiences of people with multiple sclerosis. In: Proceedings of the 2019 CHI Conference on Human Factors in Computing Systems; Glasgow, Scotland Uk. 2019 May Presented at: CHI: Conference on Human Factors in Computing Systems; May 2019; United Kingdom p. e1. [doi: 10.1145/3290605.3300357]

72. Calvo RA, Peters D, Johnson D, Rogers Y. Autonomy in technology design. In: Proceedings of CHI'14 Extended Abstracts on Human Factors in Computing Systems. 2014 Apr Presented at: CHI'14 Extended Abstracts on Human Factors in Computing Systems; April 2014; Toronto Ontario Canada p. e1 URL: https://dl.acm.org/doi/proceedings/10.1145/2559206 [doi: 10.1145/2559206]

73. Burton E, Clayville K, Goldsmith J, Mattei N, editors. The heart of the matter: patient autonomy as a model for the wellbeing of technology users. In: Proceedings of the 2019 AAAI/ACM Conference on AI, Ethics, and Society. 2019 Jan Presented at: AIES '19: Proceedings of the 2019 AAAI/ACM Conference on AI, Ethics, and Society; January 2019; Honolulu HI USA URL: https://dl.acm.org/doi/proceedings/10.1145/3306618 [doi: 10.1145/3306618.3314254]

74. Ruland CM. Handheld technology to improve patient care: evaluating a support system for preference-based care planning at the bedside. J Am Med Inform Assoc 2002;9(2):192-201 [FREE Full text] [doi: 10.1197/jamia.m0891] [Medline: $11861634]$

75. Solem IKL, Varsi C, Eide H, Kristjansdottir OB, Mirkovic J, Børøsund E, et al. Patients' needs and requirements for ehealth pain management interventions: qualitative study. J Med Internet Res 2019 Apr 01;21(4):e13205 [FREE Full text] [doi: 10.2196/13205] [Medline: $\underline{30877780]}$

76. Brewer LC, Fortuna KL, Jones C, Walker R, Hayes SN, Patten CA, et al. Back to the future: achieving health equity through health informatics and digital health. JMIR Mhealth Uhealth 2020 Jan 14;8(1):e14512 [FREE Full text] [doi: 10.2196/14512] [Medline: $\underline{31934874]}$

77. Menendez ME, Jawa A, Haas DA, Warner JJP, Codman Shoulder Society. Orthopedic surgery post COVID-19: an opportunity for innovation and transformation. J Shoulder Elbow Surg 2020 Jun;29(6):1083-1086 [FREE Full text] [doi: 10.1016/j.jse.2020.03.024] [Medline: $\underline{\text { 32312643] }}$

78. Archibald MM, Ambagtsheer RC, Casey MG, Lawless M. Using zoom videoconferencing for qualitative data collection: perceptions and experiences of researchers and participants. Int J Qual Methods 2019 Sep 11. [doi: $10.1177 / 1609406919874596]$

79. Lobe B, Morgan D, Hoffman KA. Qualitative data collection in an era of social distancing. Int J Qual Methods 2020 Jul 07. [doi: 10.1177/1609406920937875]

80. Greenhalgh T, Wherton J, Shaw S, Morrison C. Video consultations for covid-19. Br Med J 2020 Mar 12;368:e1 [FREE Full text] [doi: 10.1136/bmj.m998] [Medline: 32165352]

\section{Abbreviations}

HRA: Health Research Authority

NHS: National Health Service 
Edited by M Focsa; submitted 19.11.20; peer-reviewed by A Pattison, D Szinay, A van der Horst; comments to author 11.01.21; revised version received 25.01.21; accepted 26.01.21; published 08.03.21

Please cite as:

Robinson A, Slight RD, Husband AK, Slight SP

Designing the Optimal Digital Health Intervention for Patients'Use Before and After Elective Orthopedic Surgery: Qualitative Study $J$ Med Internet Res 2021;23(3):e25885

URL: https://www.jmir.org/2021/3/e25885

doi: $10.2196 / 25885$

PMID: 33683208

(C)Anna Robinson, Robert D Slight, Andrew K Husband, Sarah P Slight. Originally published in the Journal of Medical Internet Research (http://www.jmir.org), 08.03.2021. This is an open-access article distributed under the terms of the Creative Commons Attribution License (https://creativecommons.org/licenses/by/4.0/), which permits unrestricted use, distribution, and reproduction in any medium, provided the original work, first published in the Journal of Medical Internet Research, is properly cited. The complete bibliographic information, a link to the original publication on http://www.jmir.org/, as well as this copyright and license information must be included. 